\title{
Driving Safety Assurance Method in Work Zone Crossovers of Highway Reconstruction and Expansion Project
}

\author{
Lu Lv, ${ }^{1}$ Yanting Sheng, ${ }^{2}$ Cancan Song, ${ }^{1}$ Yongqing $\mathrm{Li}^{3},{ }^{3}$ and Zhongyin Guo $\mathbb{D}{ }^{1}$ \\ ${ }^{1}$ Key Laboratory of Road and Traffic Engineering of the Ministry of Education, Tongji University, Shanghai, China \\ ${ }^{2}$ China Airport Construction Group Northwest Design and Research Institute Co., Ltd., Xi'an, China \\ ${ }^{3}$ College of Transportation, Chang'an University, Xi'an, China \\ Correspondence should be addressed to Zhongyin Guo; zhongyin@tongji.edu.cn
}

Received 17 August 2021; Revised 20 September 2021; Accepted 12 October 2021; Published 25 October 2021

Academic Editor: Xinqiang Chen

Copyright (c) $2021 \mathrm{Lu} \mathrm{Lv}$ et al. This is an open access article distributed under the Creative Commons Attribution License, which permits unrestricted use, distribution, and reproduction in any medium, provided the original work is properly cited.

\begin{abstract}
Work zone crossover is an important area in highway reconstruction and expansion projects because it profoundly impacts the traffic safety and efficiency of the construction sites. This research sets the different median opening widths in the driving simulation experiment, collects the vehicle control signal parameters during entrance by-pass and exit by-pass, and analyzes the driving characteristics in these sections. Comparison of the driving features between the simulation experiment and the actual driving under the same median width has been also made. We should set the median width separately because the results show that driving behaviors significantly differ between entrance by-pass and exit by-pass. When the median opening width is $70 \mathrm{~m}$, the driving simulation experiment and actual driving characteristics are quite different. However, both show that driving factors of the entrance and exit by-pass are not the same. When there are two lanes in the traffic control zone and the speed limit is $60 \mathrm{~km} / \mathrm{h}$, we should set the median width at $90 \mathrm{~m}$ to ensure transportation safety.
\end{abstract}

\section{Introduction}

Freeway work zone is a hazard to workers, transportation departments, and motorists who travel through many signs, channelizing devices, and lane changes. Frequent braking, steering, and acceleration increase the risk of incidents [1]. It also causes a decrease in the traffic capacity and an increase in traffic delay [2].

Work zone traffic organization methods include closed lanes, fractions of traffic diverted to alternate routes, and crossover of diverted traffic to opposite streets [3]. Crossover of diverted traffic to opposite streets, allowing construction on all highways in one direction [4], is widely used in the interchange, bridge, and tunnel construction sites [5]. However, the traffic environment for drivers has been more complicated.

Different traffic environment has various driving characteristics, and so do driver casualty risk and work zone capacity $[6,7]$. Research on driving behavior, including vehicle speed, acceleration, deceleration, and steering wheel angle rate changes over time, analyzing the driving characteristics in work zone crossovers, can provide more relevant information to reduce the risk of travel through construction sites.

This paper aims to investigate driving characteristics through five different configurations of a work zone crossover to identify measures leading to safer conditions for drivers. The research method is a combination of the driving simulation experiment and actual investigation [8]. The focus is on work zone crossovers because this layout is critical for safety [9].

This study has designed five different median widths of driving simulation configurations. Driving characteristics changes among different work zone crossover scenarios are analyzed; we also compare the driving simulation experiments and the actual driving characteristics. The results can help engineers to optimize the ambitious safety assurance plan of work zone crossovers. 


\section{Literature Review}

Reliable traffic flow data is the foundation of driving characteristics research. Setting up traffic survey sections at construction sites [10], using drone aerial photography of the traffic control zone [11], building video-based detection infrastructure [12], and employing driving simulation experiments and traffic simulation technology to get the data that we need $[13,14]$ are all efficient methods to collect data to analyze driving characteristics in work zones.

Improving work zone capacity and reducing driving risk are two primary purposes of the driving characteristic study in construction sites.

Road work needs to occupy or compress the vehicle space, resulting in the reduction of road capacity. We can make the traffic management and control plan according to work zone capacity. Through this method, traffic delay can be relieved. Therefore, estimating work zone capacity is very important. Parametric and nonparametric models are two main approaches to estimating work zone capacity. Parametric models include nonlinear hyperbolic model [15], multiple linear regression model [16], and macro traffic flow analysis model [7]; nonparametric approach includes Gaussian kernel function model [17], neural network model [18], and aggregate decision tree model [19]. Work zone capacity prediction can use an ensemble framework to improve the modeling accuracy further [20].

Analyzing risk factors, establishing a safety evaluation model, and making a safety ensure plan constitute a flowchart of driving safety protection research [21]. Due to changes in the traffic environment in a work zone, the vehicle acceleration, deceleration, steering [22], diversion and merging [23], following, and lane changing [24] behaviors are different with the nonconstruction area. According to the merging characteristics in the transition area [25] and the following features in the activity work zone [26], through analysis of the historical accident data [27], traffic conflict technology [28] and collision severity [29] are used to a safety audit. Accident mechanisms are studied based on the vehicle speed [30] and acceleration and deceleration changes over time [31]. In addition, quantitative decision-making model can be created [32]. According to these studies, engineers can make traffic safety guarantee schemes.

Existing research seldom studies the driving behavior in work zone crossovers, precisely the difference between entrance by-pass and exit by-pass. The actual driving has not checked the result of the driving simulation. To improve the work zone crossover capacity and construction site safety, we have done this research.

\section{Material and Methods}

S29 Binlai highway lies in Shandong Province, China. The project will expand the original two-way four-lane freeway into eight lanes. Traffic flow data from different organization methods shows that mean headway and speed are the most minor, and variance is the biggest in work zone crossover. The results listed in Table 1 show that this layout is critical primarily for safety.

A driving simulation configuration is designed based on Binlai highway alignment to get driving characteristics in the work zone crossovers. Design specification for highway alignment [33] states that "the median width should not be greater than $50 \mathrm{~m}$," and the median width of this reconstruction and expansion project is $70 \mathrm{~m}$. Therefore, in this driving simulation experiment, the median width is used as a critical variable.

3.1. SCANeR Driving Simulator. The research uses the $\mathrm{SCANeR}^{\mathrm{TM}}$ studio driving simulator to do the test. The hardware has five modes: terrain, vehicle, scenario, simulation, and analysis. The simulator collects the vehicle speed, acceleration, longitude and latitude coordinates, steering wheel angle rate, force on the brake, and accelerator pedal parameters during the experiment.

3.2. Scenarios' Design. The simulation scenario has a $28 \mathrm{~km}$ highway with four lanes in one direction. The minimum radius of the circular curve is $2200 \mathrm{~m}$, and the width of the subgrade is $42 \mathrm{~m}$. The longitudinal slope is set to zero to avoid the influence on the experimental results. Five different median width scenarios $(110,50,130,90$, and $70 \mathrm{~m})$ are designed. According to "Safety Work Rules for Highway Maintenance" [34], the work zone crossover layout, including two travel lanes and a speed limit of $60 \mathrm{~km} / \mathrm{h}$, is shown in Figure 1. Some reference configuration of the traffic control zone is shown in Figure 2.

3.3. Participants. The simulation experiment recruited thirty subjects to participate in the research $(22$ men and 8 women). Age varied between 23 years and 30 years (mean value: 24.4 years; standard deviation: 1.82 years). Their driving experience ranged between 1.2 years and 6 years (mean value: 3.3 years; standard deviation: 1.46 years). Before the experiment, they needed to pass a 3 kilometer preexperimental road to adapt to the essential operation of the simulator.

The sample size for the driving simulation experiment is 30. We use power analysis to statistically determine whether the number of participants is sufficient for this study. A confidence level of $90 \%$ and an effect size of 0.7 are used in power analysis to balance power and effect size. Results showed that the sample size had a statistical power of 0.849 , more significant than 0.80 [35]. This result implied that the sample size of the driving simulation experiment could meet the statistical requirement.

3.4. Data Collection and Analysis. The driving simulation experiment uses a passenger car as the test vehicle. The sampling frequency is set to $50 \mathrm{~Hz}$ to obtain the control signal in the experiment process. Let longitude along the road be $X$ direction and crossroad be $Y$ direction. Sampling 
TABle 1: Traffic flow data about different construction sites.

\begin{tabular}{|c|c|c|c|c|c|}
\hline \multirow{2}{*}{ Construction sites } & \multirow{2}{*}{ Traffic organization } & \multicolumn{2}{|c|}{ Headway (s) } & \multicolumn{2}{|c|}{ Speed $(\mathrm{km} / \mathrm{h})$} \\
\hline & & Mean & Variance & Mean & Variance \\
\hline Subgrade widened & Compress right lane & 5.63 & 5.06 & 78.08 & 10.77 \\
\hline Bridge widened & Closed shoulder & 8.98 & 7.65 & 76.82 & 10.54 \\
\hline One direction closed & Work zone crossover & 10.43 & 8.86 & 66.46 & 10.98 \\
\hline Subgrade left & Closed shoulder & 5.20 & 4.36 & 75.33 & 9.88 \\
\hline Construction overpass & Compress left lane & 5.55 & 5.14 & 73.56 & 8.41 \\
\hline
\end{tabular}

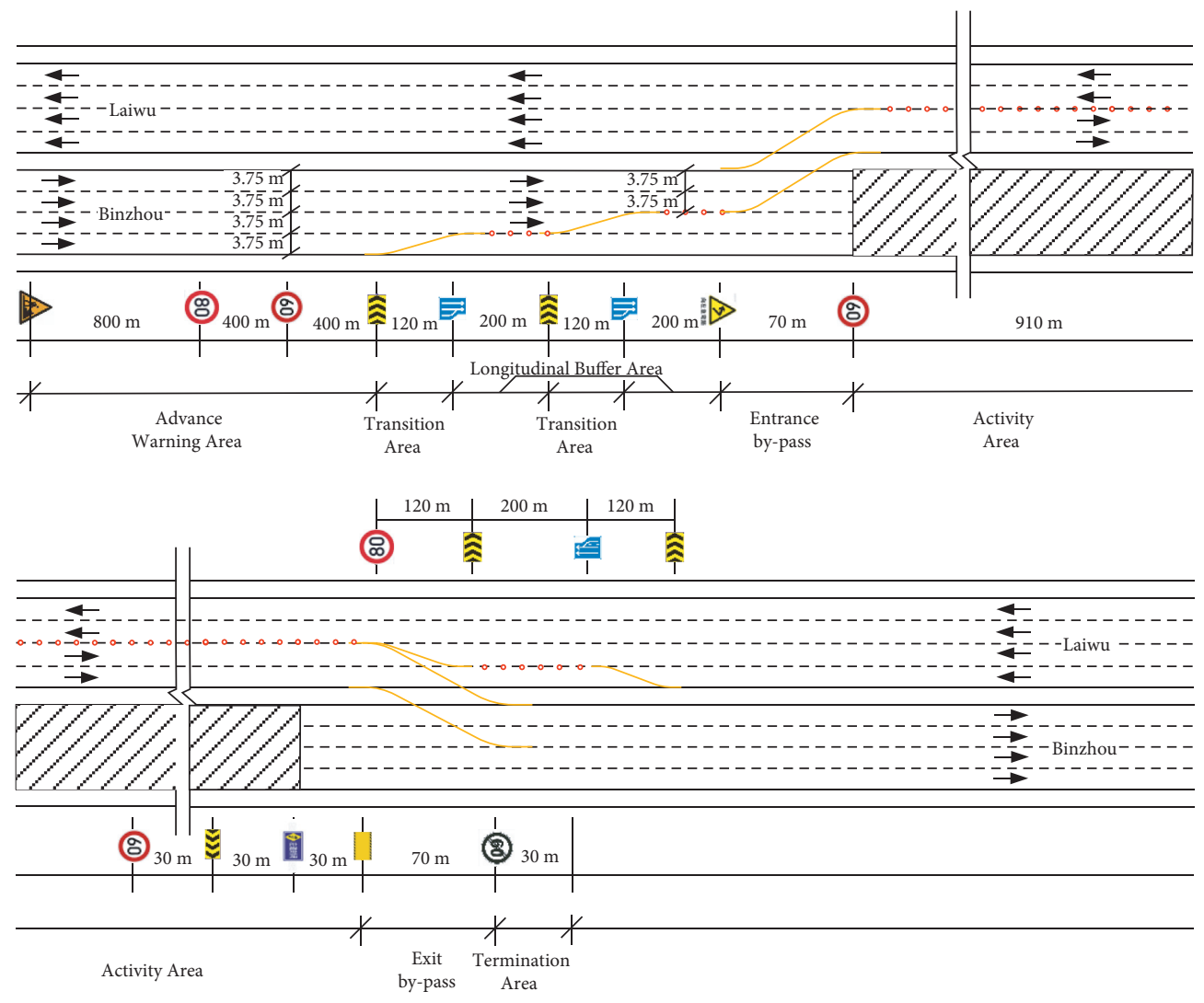

FIgURE 1: Work zone crossover layout.

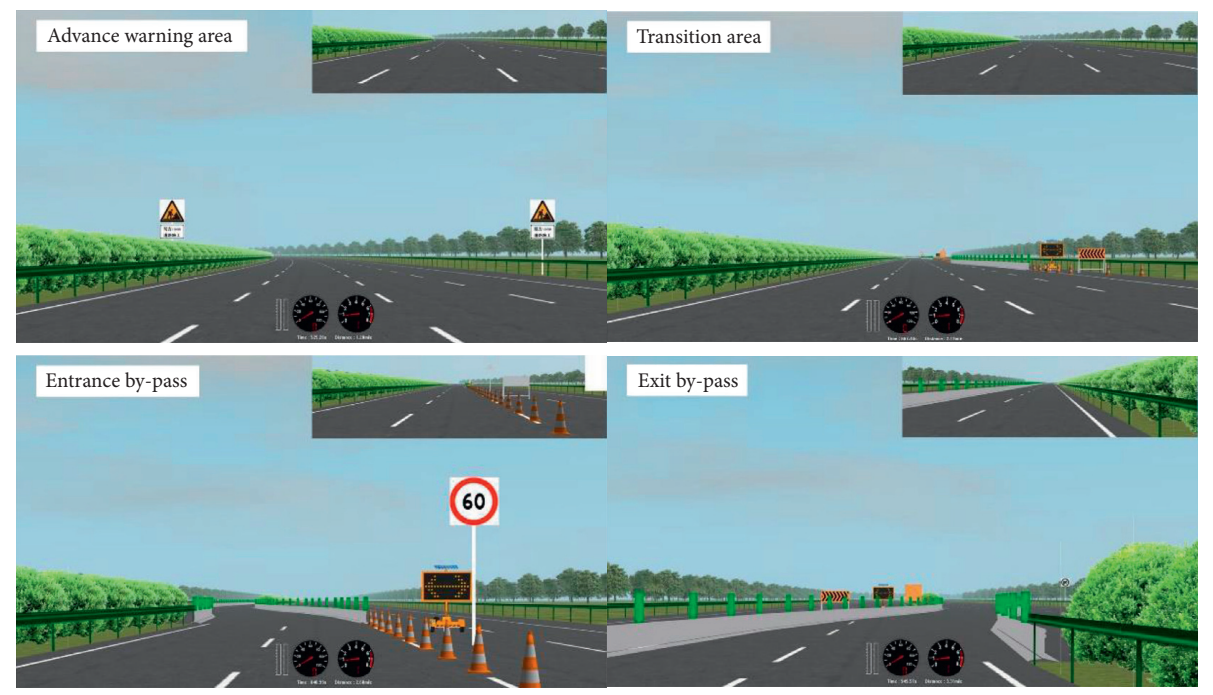

Figure 2: Traffic control zone reference configuration. 
time, pile position, steering wheel angle rate, distance from lane center, speed, and acceleration in longitude and crossroad are output. The output parameters of the driving simulation experiment are listed in Table 2.

3.5. Methodology. Driving comfort, traffic safety, and driving workload are three critical parameters in evaluating highway performance. According to the traffic data of different simulation scenarios, we can study the driving characteristics of the work zone crossover.

The absolute value of the speed gradient reflects the vehicle speed change rate. In the work zone crossovers, drivers need to slow down within a short distance to ensure safety, and the larger deceleration amplitude will be hazardous to driving comfort. Therefore, the absolute value of the speed gradient can reflect the driving comfort of the measurement site. The absolute value of the speed gradient at each measurement site is computed as follows [36]:

$$
\left|\Delta I_{v}\right|=\frac{\left|\Delta v_{85}\right|}{L_{i}} \times 100 \%,
$$

where $\left|\Delta I_{v}\right|$ is the absolute value of speed gradient; $\left|\Delta v_{85}\right|$ is the absolute value of $85 \%$ percentile vehicle speed difference between the start and endpoints of the analysis unit; and $L_{i}$ is the length of the deceleration section.

If the absolute value of speed gradient is speed change in spatial range, then the deceleration is speed decrease in temporal range. Generally speaking, the sharp slowdown is more dangerous. By calculating the ratio of length whose slowdown is greater than the limit value to the median width, the cumulative driving risk in each driving configuration can be calculated as [37]

$$
C_{r}=\frac{L_{a}}{L_{m}} \times 100 \%,
$$

where $L_{a}$ is the length of the section whose deceleration is greater than the limit value; $L_{m}$ is the median width; and $C_{r}$ is the ratio of $L_{a}$ to $L_{m}$.

This paper uses the high-frequency energy of the steering wheel angle rate to characterize workload in different work zone crossovers. The original signal is decomposed into low frequency and high frequency based on wavelet transform. The energy spectrum variations of each layer are calculated through autocorrelation function and Fourier transform. Reconstruction of the wavelet contains high-frequency energy and averages the new wavelet spectrum density functions, the result of which is the driving workload in each simulation configuration.

\section{Results and Discussion}

Driving behavior is the continuous driving state of the vehicle, including changes in velocity, distance and time headway, acceleration, and deceleration. Driving characteristics refer to the vehicle behavior in a specific environment, including operating speed and steering characteristics. The traffic environment has a significant impact on driving behavior. Different traffic environment leads to other driving behaviors. Consequently, different traffic environment has different characteristics. Vehicle behavior is the basis of the research on the driving characteristics in work zone crossover.

4.1. Driving Behavior Analysis. Driving behaviors such as speed, deceleration, and steering wheel angle rate generated by the vehicle reflect the driving characteristics of the work zone crossover. The analysis of the driving behavior can provide more relative information to driving features in work zone crossover. A statistical method of key behavior parameters in this paper is presented in Table 3.

\subsubsection{Speed}

(1) Initial Speed. Vehicle speed is the function of the traffic environment. It can reflect the risk of driving. Initial vehicle speed increases with the median width (Figure 3(a)), and it is more significant in exit by-pass than in entrance by-pass. The initial speed difference between entrance and exit bypass decreases with the median width. The average speed of each configuration indicates higher speed limit compliance in a driving simulation experiment.

(2) Slowdown Amplitude. Work zone crossover is similar in driving behavior to lane changing. Their driving speed decreases at first and then increases after entering the target lane. If the driver realizes the safety risk, they will slow down. Therefore, the more the slowdown amplitude is, the more the considerable driving risk will be. Slowdown amplitude is the biggest and smallest when the entrance by-pass median width is $130 \mathrm{~m}$ and $90 \mathrm{~m}$, respectively. The exit by-pass is $110 \mathrm{~m}$ and $90 \mathrm{~m}$, respectively (Figure 3(b)).

The reason is that when the entrance by-pass median width is less than $90 \mathrm{~m}$, the traffic environment cannot satisfy the driver's expected velocity, so they have to slow down to avoid collision. When the median width is more than $90 \mathrm{~m}$, the driver exits by-pass at high speed. Nevertheless, to enter the target lane smoothly, they have to slow down.

4.1.2. Deceleration. Deceleration and related indicators reflect the change in the driving environment and can be used to evaluate the driving risk. Deceleration in this paper is the absolute value of the longitudinal deceleration.

(1) $15 \%$ Percentile Deceleration. $15 \%$ percentile deceleration changes with the median width are shown in Figure 4(a). The more the driving risk the driver realizes, the greater the car's deceleration. Accordingly, driving risk is highest when the entrance by-pass median width is $50 \mathrm{~m}$ and the exit median width is $130 \mathrm{~m}$ separately. The reason for this result is the same as slowdown amplitude changes with median width.

(2) Deceleration Rate. The deceleration is always negative when the vehicle stops, but the deceleration rate is either positive or negative. The deceleration rate in exit by-pass is greater than that in entrance by-pass (Figure 4(b)), indicating that the slowdown process in entrance by-pass is smoother. 
TABLE 2: Output parameters of driving simulation experiment.

\begin{tabular}{lccccccc}
\hline Time & $\begin{array}{c}\text { Pile position } \\
\mathrm{m}\end{array}$ & $\begin{array}{c}\text { Speed } / X \\
\text { direction } \\
\mathrm{km} / \mathrm{h}\end{array}$ & $\begin{array}{c}\text { Speed } / Y \\
\text { direction } \\
\mathrm{km} / \mathrm{h}\end{array}$ & $\begin{array}{c}\text { Steering wheel } \\
\text { angel rate } \\
\%\end{array}$ & $\begin{array}{c}\text { Distance from } \\
\text { lane center } \\
\mathrm{m}\end{array}$ & $\begin{array}{c}\text { Acceleration } / X \\
\text { direction } \\
\mathrm{m} / \mathrm{s}^{2}\end{array}$ & $\begin{array}{c}\text { Acceleration } / Y \\
\text { direction } \\
\mathrm{m} / \mathrm{s}^{2}\end{array}$ \\
\hline 126.982 & 3447.10 & 119.12 & -0.09 & -12.77 & -0.10 & 0.16 & 0.23 \\
127.003 & 3447.80 & 119.13 & -0.10 & -13.44 & -0.09 & 0.16 & 0.16 \\
127.023 & 3448.46 & 119.14 & -0.10 & -16.41 & -0.09 & 0.16 \\
127.042 & 3449.10 & 119.15 & -0.10 & -13.89 & -0.08 & 0.16 \\
127.062 & 3449.76 & 119.17 & -0.10 & -14.45 & -0.07 & 0.24 \\
\hline
\end{tabular}

TABLE 3: Statistical method of key behavior parameters.

\begin{tabular}{|c|c|}
\hline Key behavior parameters & Statistical method \\
\hline Initial speed $\left(v_{\text {in }}\right)$ & $\begin{array}{c}\text { The instantaneous speed when the vehicle's rear passes through the start line of the } \\
\text { entrance or exit by-pass }\end{array}$ \\
\hline Slowdown amplitude $(\Delta v)$ & The difference between initial speed and minimum speed in work zone crossover \\
\hline Deceleration $(a)$ & $15 \%$ percentile deceleration in the work zone crossover \\
\hline Deceleration rate $(J)$ & $15 \%$ percentile deceleration rate in the work zone crossover \\
\hline Maximum deceleration rate difference $(P)$ & $\begin{array}{l}\text { The difference between maximum and minimum deceleration rate in the work zone } \\
\text { crossover }\end{array}$ \\
\hline Maximum steering wheel angel rate $(S)$ & The maximum steering wheel angel rate in the work zone crossover \\
\hline
\end{tabular}

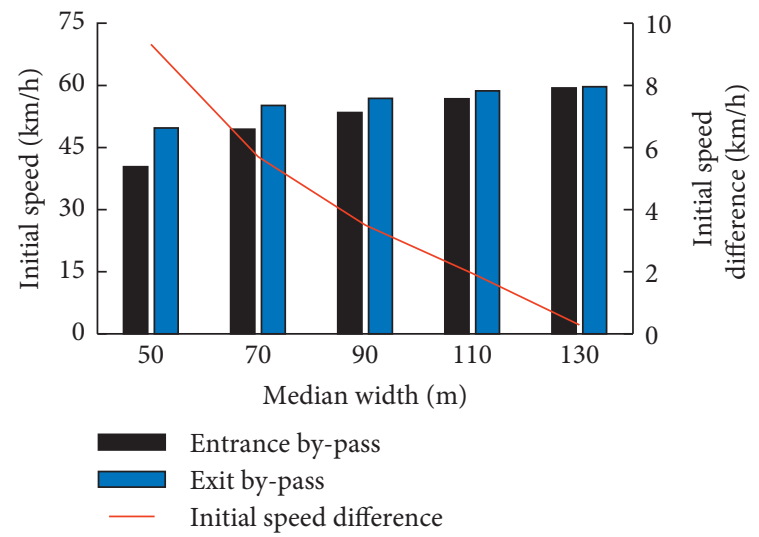

(a)

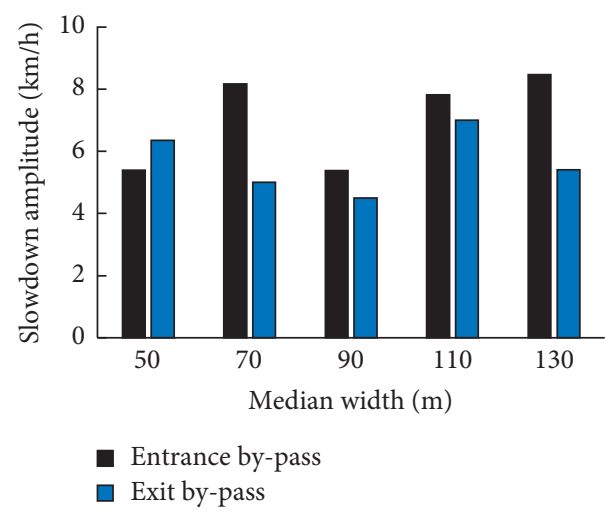

(b)

FIGURE 3: Speed parameters' change with median width: (a) average initial speed; (b) slowdown amplitude.

(3) Maximum Deceleration Rate Difference. The maximum deceleration rate difference reflects the amplitude of change in the deceleration rate. Compared with Figure 4(b), the maximum deceleration rate difference is more negligible among different median widths, in entrance and exit by-pass. The maximum deceleration rate difference is more significant in the exit by-pass than in the entrance by-pass. Both have the smallest value when the median width is $90 \mathrm{~m}$ (Figure $4(\mathrm{c})$ ).

4.1.3. Maximum Steering Wheel Angel Rate. The driving workload increases when the driver continuously steers in the work zone crossover to complete the lane change. Maximum steering wheel angle rate grows with the median width in entrance by-pass slowly but decreases with the median width in exit by-pass quickly (Figure 5). The maximum steering wheel angle rate of the exit by-pass is 2.5 times that of the entrance by-pass when the median width is $50 \mathrm{~m}$; it is 1.85 times that of the entrance by-pass when the median width is $130 \mathrm{~m}$.

In conclusion, driving characteristics in entrance by-pass are significantly different from those in exit by-pass.

4.2. Driving Characteristics in Work Zone Crossovers. Driving behavior is affected by the traffic environment, vehicle performance, driver's personality, and experience. Because driving behavior is closely related to the traffic environment, we can study the driving characteristics in a specific scenario by the driving simulator. Consistency of operating speed, deceleration, and high-frequency energy of steering wheel angle rate is used to evaluate the driving comfort, traffic safety, workload separately in work zone crossover. 


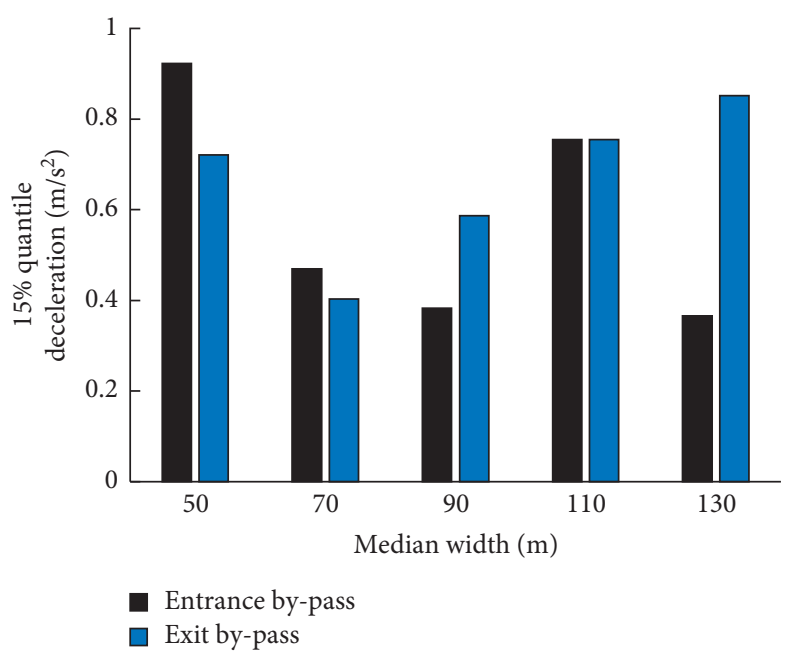

(a)

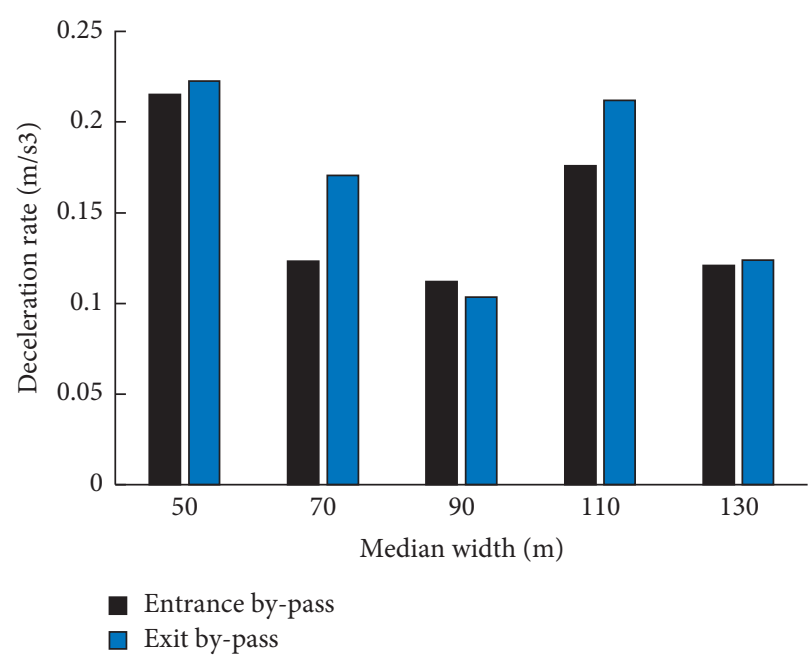

(b)

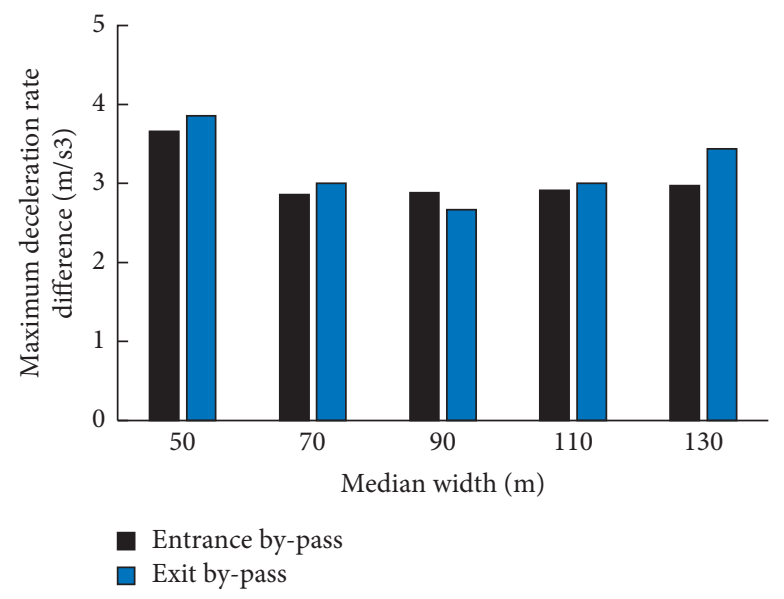

(c)

Figure 4: Deceleration parameters' change with median width: (a) 15\% quantile deceleration; (b) deceleration rate; (c) maximum deceleration rate difference.

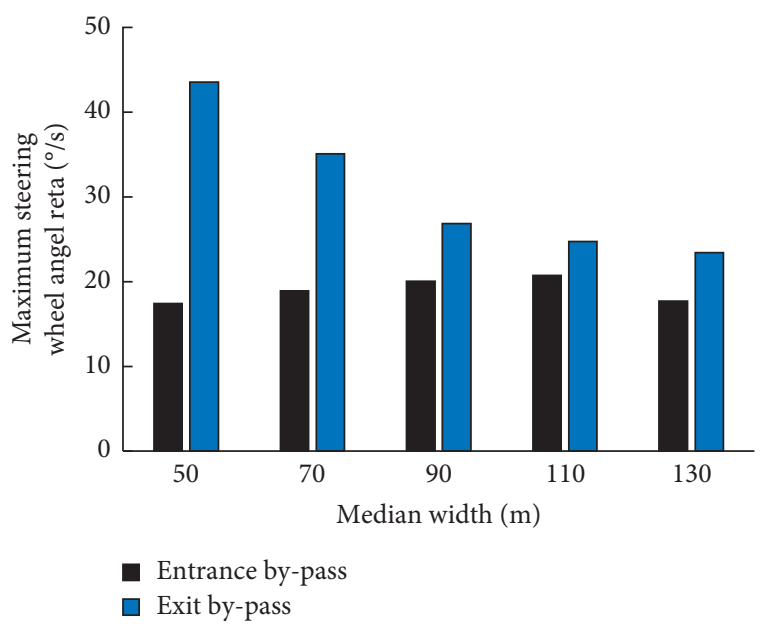

FIGURE 5: Steering wheel angel rate changes with median width.
4.2.1. Consistency of Operating Speed. Divide the median width into five sections, and use the normalized average speed of each section to represent the operating speed. The speed decreases first and then increases after both entrance and exit by-pass changes with segmentation (Figure 6(a)).

All scenarios' deceleration section $L_{i}$ can be obtained from Figure 6. Consistency values of operating speed in entrance and exit by-pass among different median widths according to equation (1) are listed in the last column of Table 4.

$\left|\Delta v_{85}\right| \leq 20(\mathrm{~km} / \mathrm{h})$ and $\left|\Delta I_{v}\right| \leq 10(\mathrm{~km} / \mathrm{h} / \mathrm{m})$ are two criteria to evaluate the highway consistency of the operation speed. Only some of the simulation scenarios satisfy these criteria (Table 4). $v_{\text {in }}$ and $v_{\text {out }}$ increase with the median width. Both of them are greater in exit by-pass than in entrance by-pass at the same median width. Their variation tendency is noticeable compared to the $\left|\Delta v_{85}\right|$ and $\left|\Delta I_{v}\right|$ change with the median width. 


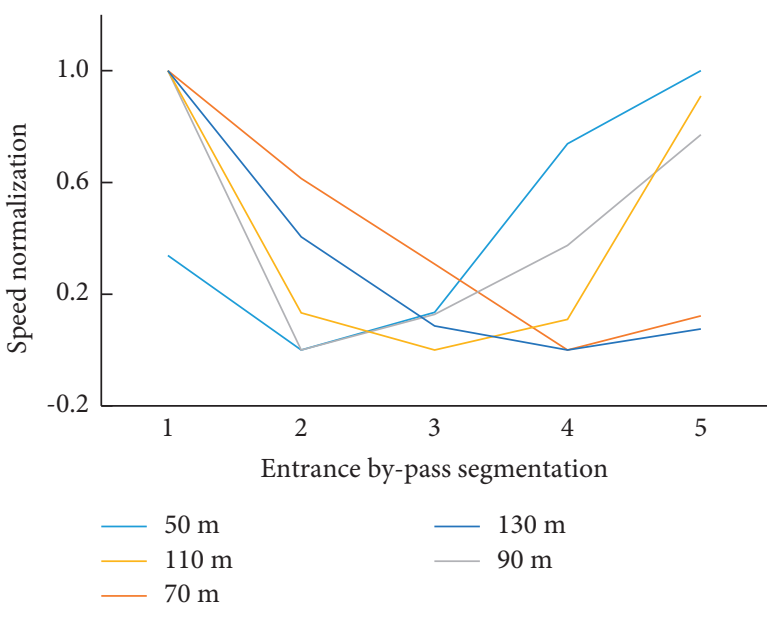

(a)

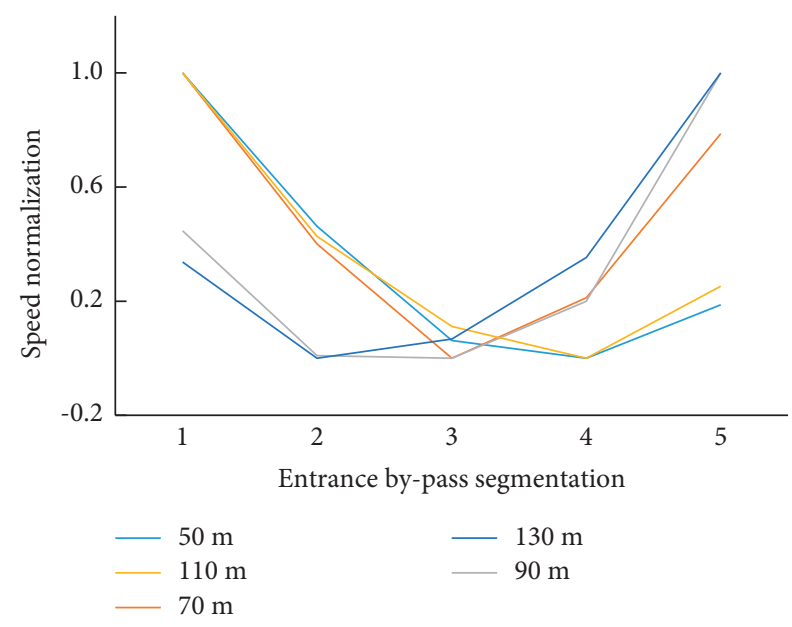

(b)

FIgURE 6: Vehicle speed changes with median width in (a) entrance by-pass and (b) exit by-pass.

TABle 4: $\left|\Delta I_{v}\right|$ distribution in entrance and exit by-pass among different median widths.

\begin{tabular}{ccccccc}
\hline \multicolumn{2}{c}{ Median width (m) } & $v_{\text {in }}$ & $v_{\text {out }}$ & $\left|\Delta v_{85}\right|$ & $L_{i}$ & $\left|\Delta I_{v}\right|$ \\
\hline \multirow{2}{*}{50} & Entrance by-pass** $^{* *}$ & 40.35 & 43.17 & 12.57 & 12.5 & 100.56 \\
& Exit by-pass* $^{*}$ & 49.66 & 45.50 & 8.58 & 37.5 & 22.89 \\
\hline \multirow{2}{*}{70} & Entrance by-pass* $^{*}$ & 49.40 & 44.83 & 6.10 & 52.5 & 11.63 \\
& Exit by-pass & 55.11 & 52.80 & 3.50 & 35 & 10.00 \\
\hline \multirow{2}{*}{90} & Entrance by-pass** $^{* *}$ & 53.39 & 52.22 & 13.96 & 22.5 & 62.02 \\
& Exit by-pass** & 56.89 & 55.81 & 10.62 & 45 & 23.59 \\
\hline \multirow{2}{*}{110} & Entrance by-pass & 56.71 & 54.20 & 2.21 & 55 & 4.01 \\
& Exit by-pass & 58.66 & 60.15 & 5.27 & 82.5 & 6.39 \\
\hline \multirow{2}{*}{130} & Entrance by-pass & 59.36 & 58.19 & 5.75 & 97.5 & 5.90 \\
& Exit by-pass & 59.64 & 57.53 & 2.20 & 32.5 & 6.76 \\
\hline
\end{tabular}

Note. $v_{\text {in }}$ is the initial speed of the entrance or exit by-pass; $v_{\text {out }}$ is the speed at the end of the deceleration section. ${ }^{* *}$ Neither $\left|\Delta v_{85}\right|$ nor $\left|\Delta I_{v}\right|$ satisfies the consistency of the operating speed. * One of the two parameters meets the consistency of the operating speed.

4.2.2. Distribution of Deceleration. The change of the deceleration with time can reflect the real-time driving risk. Cumulative frequency deceleration reveals the distribution of the driving risk. The distribution characteristics of the cumulative frequency deceleration curve in various traffic environments are different (Figure 7).

The earlier the knee in cumulative frequency curve is, the higher the ratio of the deceleration in high range is, which means that the driving risk of that scenario is greater. In all driving simulation scenarios, the knee in cumulative frequency curve is after $85 \%$ percentile (Figure 7 ). Therefore, we can set $85 \%$ percentile cumulative frequency deceleration as the limit value in equation (2). The result of cumulative driving risk in each driving configuration is provided in the last column of Table 5 .

Cumulative driving risk in entrance by-pass from the highest to the lowest order is the median width equal to $130 \mathrm{~m}, 70 \mathrm{~m}, 110 \mathrm{~m}, 50 \mathrm{~m}$, and $90 \mathrm{~m}$. Similarly, cumulative driving risk in exit by-pass from the highest to the lowest order is the median width equal to $70 \mathrm{~m}, 110 \mathrm{~m}, 50 \mathrm{~m}$,
$130 \mathrm{~m}$, and $90 \mathrm{~m}$ (Table 5). The average value of the cumulative driving risk in entrance and exit by-pass is $19.73 \%$ and $25.33 \%$. The cumulative driving risk gets the smallest value in entrance and exit by-pass when the median width is $90 \mathrm{~m}$.

4.2.3. Driving Workload. The steering wheel angle rate is decomposed into 5 layers using a Haar wavelet. The original signal $s=\sum_{i=1}^{5} d_{i}+a_{i}$, where $d_{i}$ is the detail coefficient of each level and $a_{5}$ is the approximation coefficient. All detail and approximation coefficients of the wavelet power are illustrated in Figure 8. The original signal is the steering wheel angle rate when a driver passes through the entrance by-pass whose median width is $70 \mathrm{~m}$.

The demarcation point of the high- and low-frequency energy is $50 \mathrm{~Hz}$. The power is more elevated in high-frequency energy. Therefore, the wavelet can be reconstructed with the first 4 layers to represent the entrance and exit bypass driving workload (Figure 8 ). The average of the power spectrum density function is more excellent; the driving workload is higher.

The entrance and exit by-pass driving workload decrease with the median width (Figure 9), but the results do not conform to this law when the median width is $130 \mathrm{~m}$. Because the longitudinal distance required for free vehicle lane changing is usually close to $130 \mathrm{~m} \mathrm{[38],} \mathrm{at} \mathrm{this} \mathrm{time,} \mathrm{the}$ vehicle speed is high, and the sudden direction adjustment at the exit by-pass leads to increased driving workload. In general, the driving workload and data dispersion in the exit by-pass are more significant than in the entrance one. This points to one problem: driving in exit by-pass takes more energy from the driver than the entrance by-pass section.

4.3. Results of Driving Simulation Experiment and Actual Driving Comparison. Hovering drone photographs the work zone crossovers, and vehicle trajectory is extracted through video analysis technology (Figure 10). 19 trucks and 79 small 


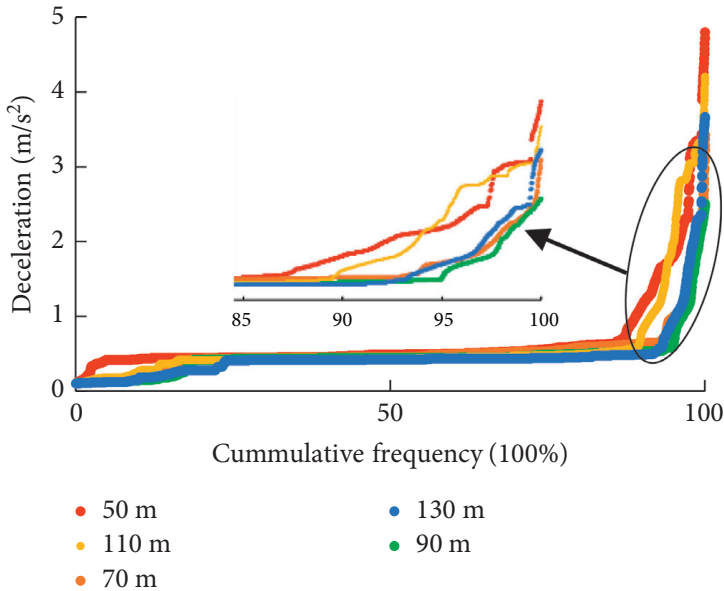

(a)

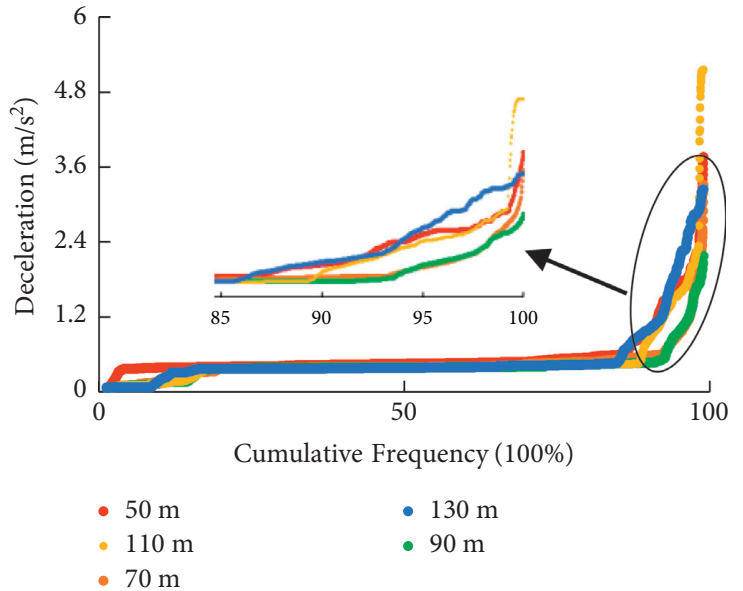

(b)

Figure 7: Deceleration cumulative frequency in (a) entrance by-pass and (b) exit by-pass.

TABLE 5: Cumulative driving risk in each driving configuration.

\begin{tabular}{lcccc}
\hline & Median width $(\mathrm{m})$ & $a_{85}$ & $L_{a}$ & $C_{r}(\%)$ \\
\hline \multirow{2}{*}{50} & Entrance by-pass & 0.53 & 6.34 & 12.68 \\
& Exit by-pass & 0.54 & 11.25 & 22.50 \\
\hline \multirow{2}{*}{70} & Entrance by-pass & 0.50 & 16.65 & 27.15 \\
\\
\multirow{2}{*}{90} & Exit by-pass & 0.46 & 9.79 & 38.79 \\
\hline \multirow{2}{*}{110} & Entrance by-pass & 0.41 & 17.06 & 10.88 \\
& Exit by-pass & 0.40 & 21.03 & 18.95 \\
\hline \multirow{2}{*}{130} & Entrance by-pass & 0.42 & 31.43 & \\
& Exit by-pass & 0.39 & 34.99 & 28.57 \\
\hline
\end{tabular}

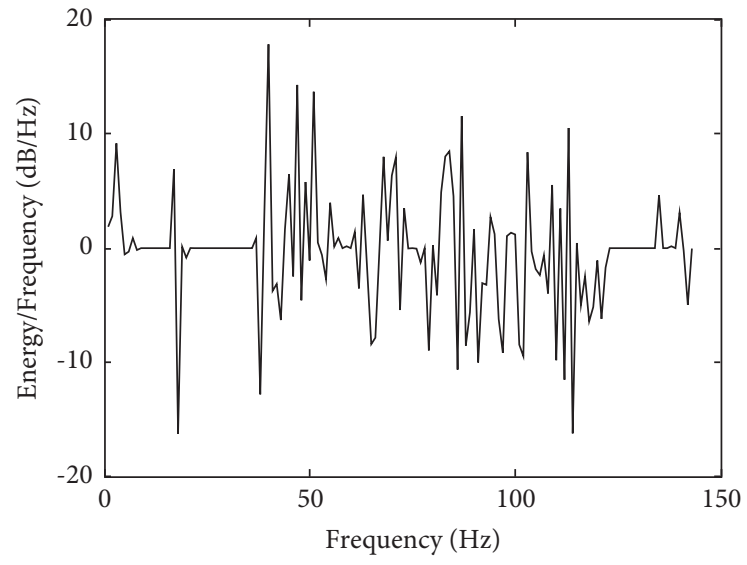

(a)

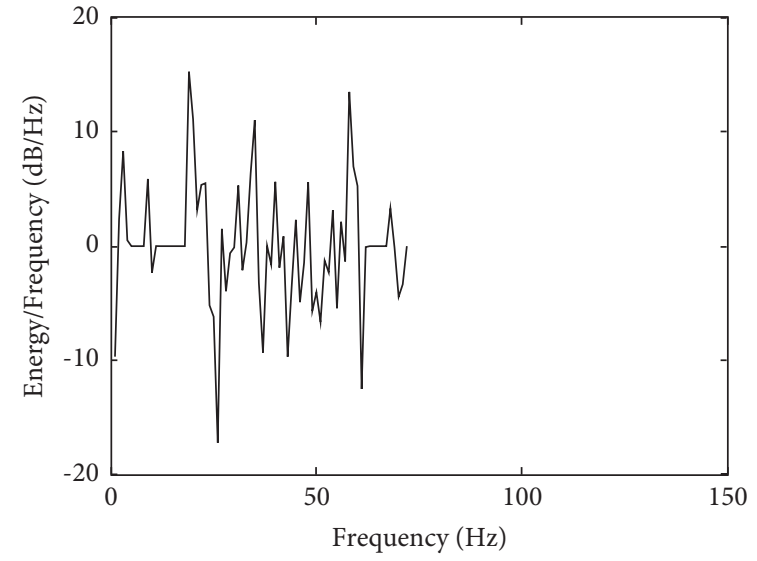

(b)

Figure 8: Continued. 


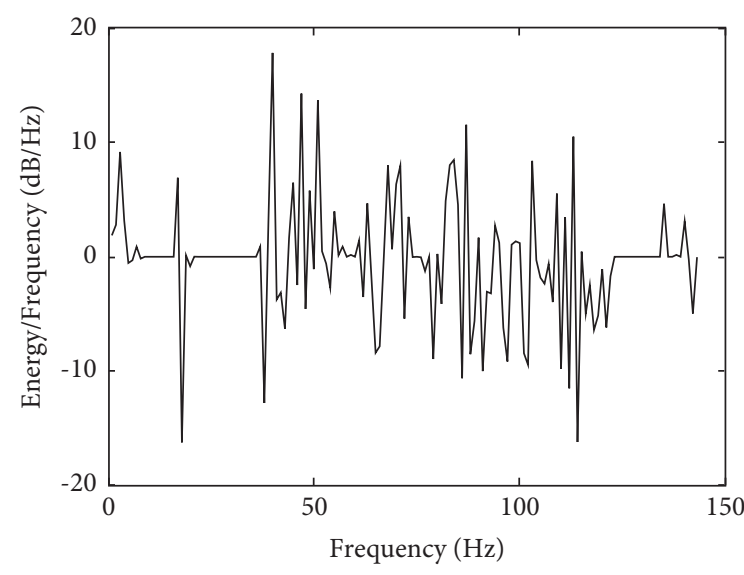

(c)

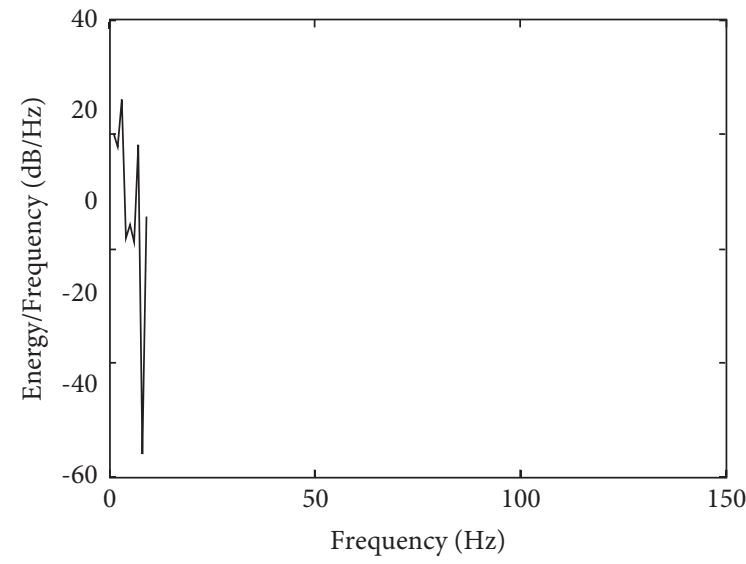

(e)

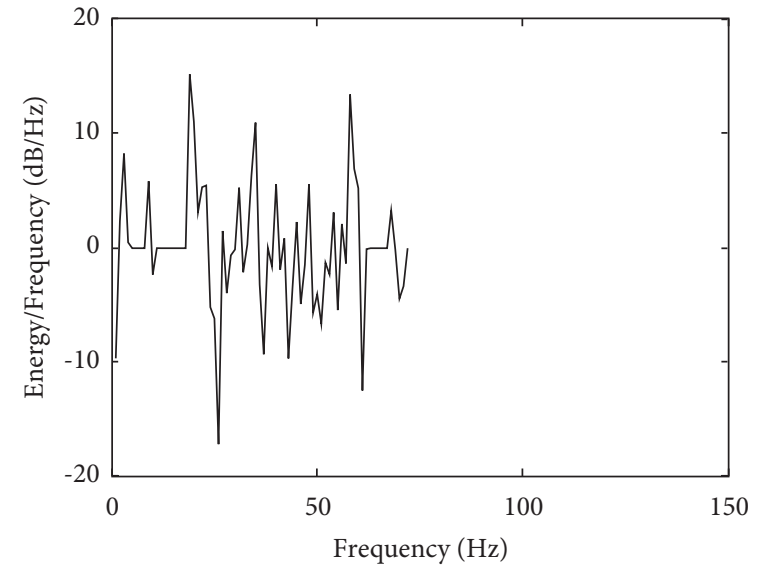

(d)

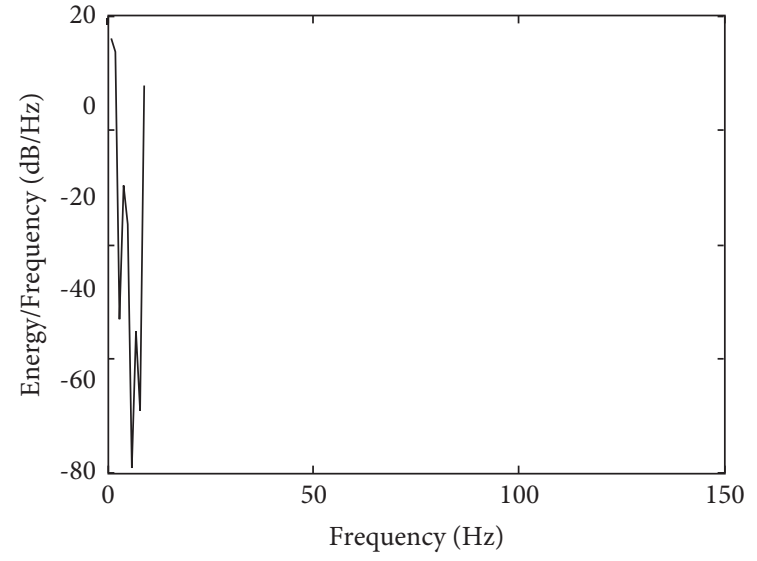

(f)

FIGURE 8: Wavelet power of steering wheel angel rate in $70 \mathrm{~m}$ median width entrance by-pass.

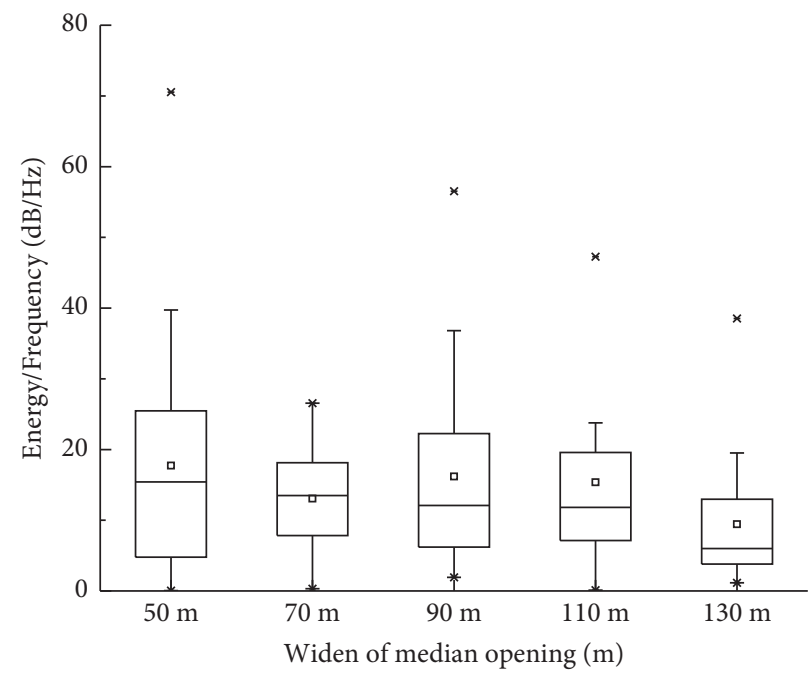

(a)

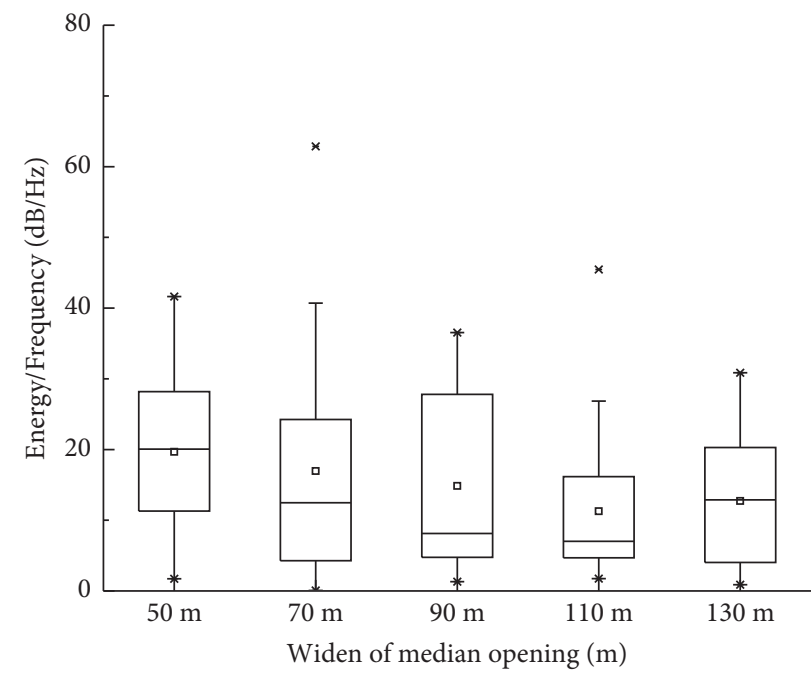

(b)

Figure 9: Driving workload box diagram of different simulation configurations: (a) entrance by-pass; (b) exit by-pass. 


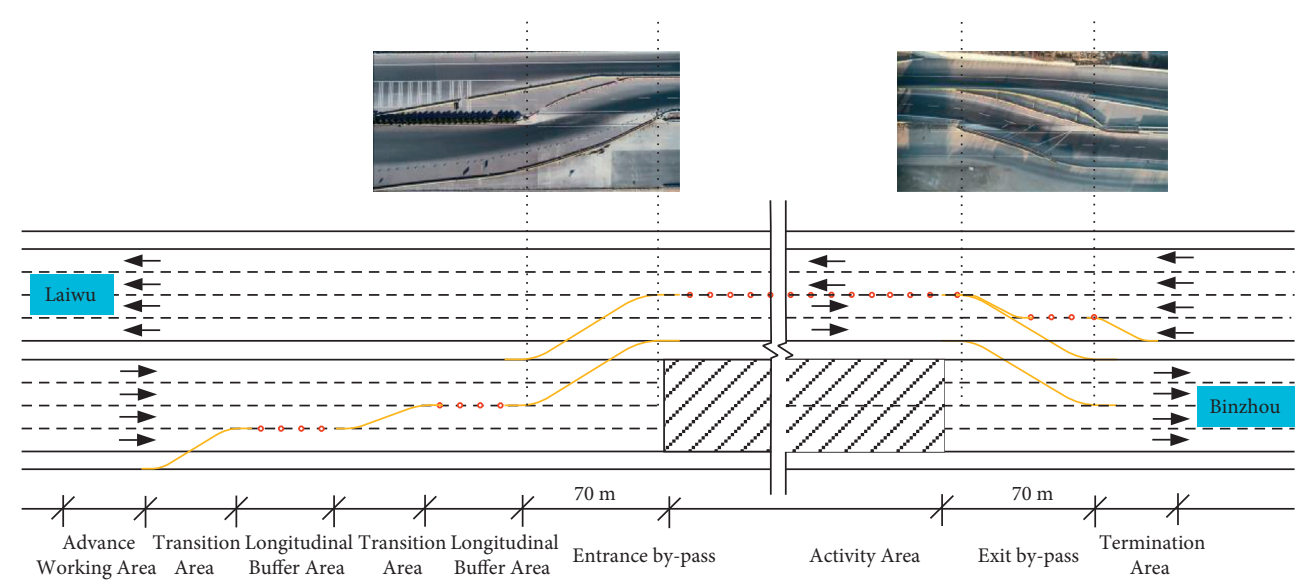

FIGURE 10: Hovering drone photography area and data extraction range.

TABLE 6: Relative difference between driving simulation and actual driving.

\begin{tabular}{|c|c|c|c|c|c|c|}
\hline \multirow[b]{2}{*}{ Parameters } & \multicolumn{3}{|c|}{ Entrance by-pass } & \multicolumn{3}{|c|}{ Exit by-pass } \\
\hline & $\begin{array}{l}\text { Driving simulation } \\
(\%)\end{array}$ & $\begin{array}{c}\text { Actual driving } \\
(\%)\end{array}$ & $\begin{array}{c}\text { Relative difference } \\
(\%)\end{array}$ & $\begin{array}{l}\text { Driving simulation } \\
(\%)\end{array}$ & $\begin{array}{c}\text { Actual driving } \\
\text { (\%) }\end{array}$ & $\begin{array}{l}\text { Relative difference } \\
(\%)\end{array}$ \\
\hline$\left|\Delta I_{v}\right|$ & 11.63 & 10.19 & 12.38 & 10 & 0.83 & 91.70 \\
\hline$C_{r}$ & 23.79 & 82.09 & $>100$ & 38.79 & 49.06 & 26.48 \\
\hline Workload & 13.07 & 1.05 & 91.97 & 16.95 & 0.40 & 97.64 \\
\hline
\end{tabular}

Note. Out of all the 45 free travel cars in exit by-pass in actual driving; 14 of them did not slow down. Therefore, the first two parameters of the exit by-pass only contain 31 cars.

passenger cars tracks are collected from the entrance bypass, and 15 trucks and 54 cars tracks are gathered from the exit by-pass. 67 free travel cars in entrance by-pass and 45 free travel cars in exit by-pass have been sifted based on the time headway significant than $10 \mathrm{~s}$.

The absolute values of the operation speed gradient $\left|\Delta I_{v}\right|$, cumulative driving risk $C_{r}$, and the driving workload are calculated using these free travel tracks' data. Their relative difference between driving simulation and actual driving is shown in Table 6.

Driving characteristics are significantly different between driving simulation and actual driving (Table 6). There are three main reasons. First, the absence of speed limit signs in the real work zone leads to the vehicle's slight slowdown in exit by-pass; this results in a small calculation of the speed gradient absolute. Second, in the actual driving scenario entrance by-pass, most drivers continue to slow down, which leads to greater cumulative driving risk. Third, the work zone crossover marking is missing in actual driving; the shape of the work zone crossover layout is an ellipse arc, making the turning radius bigger and the driving workload smaller. In addition, the effectiveness of the driving simulation is also a critical reason that makes a difference between the two.

However, driving characteristics of entrance by-pass and exit by-pass are significantly different in actual driving. This conclusion is still consistent with the driving simulation experiment.

The effectiveness of driving simulation includes the efficacy of the test paradigm, content-related usefulness, and structure effectiveness. Compared with the relative and absolute point of the driving simulation and actual driving experiment, the validity of the driving simulation experiment design is more important [39].

It is difficult for the driving simulation to achieve absolute effectiveness, and the relative efficacy to traffic research is enough [40]. By comparing the speed and speed standard deviation, vehicle position and position change, line crossing, and lane-changing behavior between driving simulation and actual driving, it is found that the vehicle behavior in driving simulation and actual driving is consistent.

Although there are differences between the driving simulation and actual driving, based on ensuring the similarity between the driving simulation and actual vehicle driving, under the driving simulation conditions, the experimental conclusion obtained in driving simulation can be used in engineering practice.

\section{Conclusions}

The results achieved in the driving simulation and the actual driving study confirmed that the driving behaviors in work zone crossover have a more significant impact on driving comfort, traffic safety, and driving workload.

The absolute operation speed gradient changing trend is similar to "wave" with the decline in fluctuation with the median width. Consistency of the operation speed is satisfied when the median width is $110 \mathrm{~m}$ in entrance and exit bypass. Driving comfort is better at these points. 
The cumulative driving risk is the smallest when the median width is $90 \mathrm{~m}$ in entrance and exit by-pass. Traffic is the safest at these configurations.

The frequency of the steering wheel angle rate decreases with the median width, which means the longer the median width, the smaller the driving workload. The driving workload in exit by-pass is more significant than that in entrance by-pass when the median width is the same.

Due to the difference between driving simulation and actual driving, their driving characteristics have a significant difference. Although both of them have the same results, there is a considerable difference between entrance by-pass and exit by-pass in work zone crossovers. Besides the channelizing devices and drivers' psychological changes, such differences may also occur due to the difference between left and right turn behaviors. Therefore, the closed lanes in different directions should be also used as experimental variables, and their results should be compared.

The analysis results have shown that driving comfort is better and workload is smaller with the median width, but this regulation is inconsistent with traffic safety evaluation results. There are considerable differences in operating characteristics when the median width is identical, which indicates that median width in entrance by-pass and exit bypass should be set separately in traffic organization of the reconstruction and expansion project. There is a greater risk in exit by-pass where drivers are less vigilant than in entrance by-pass. Therefore, we should strengthen the speed limit compliance management in exit by-pass.

The evaluation criteria determine the median width of the work zone crossover. Under the conditions that there are two lanes in the traffic work zone and the speed limit is $60 \mathrm{~km} / \mathrm{h}$, the median width should be $90 \mathrm{~m}$ to prioritize safety.

The research results in Section 4.2 show that the driving comfort and traffic safety index values of entrance and exit by-pass are nonlinear with the change of the median width, and the workload shows a monotonic relationship with the evolution of the median width. The median width is different with the different evaluation index optimal values.

Compared with the driving comfort and workload, driving safety is an important index that needs to be guaranteed in priority in the work zone crossover. Under the strict implementation of the speed limit measures in the construction area, the driving speed is low, and the contradiction between driving comfort and workload is not prominent. Because the traffic safety evaluation index has a nonlinear relationship with the median width, we can only obtain the appropriate median width according to the driving simulation experiment.

The results achieved with this research refer to a sample of 30 subjects aged between 23 and 30 years old. The younger the drivers, the less their driving experience and the greater the chance of dangerous driving behavior. Accordingly, higher requirements of the median width are needed. When the median width can ensure the driving safety of younger drivers, it can provide the driving safety of most drivers. Further evaluation of the impact of other driver groups, such as younger and older drivers, should be appropriate to confirm the driving behavior recorded in this study.
Furthermore, the median width in actual driving is a single value. More median widths should be surveyed to research the driving characteristics in work zone crossover in real driving, and these results should be used to optimize the organization of the work zone crossover in highway reconstruction and expansion projects.

\section{Data Availability}

The data used to support the findings of this study are included in the article.

\section{Conflicts of Interest}

The authors declare no conflicts of interest.

\section{Acknowledgments}

This paper is based on a research project sponsored by the Science and Technology Planning Project of the Communications Department of Shandong Province (2019B32), National Natural Science Foundation of China (51978069), Key Research and Development Plan of Shaanxi Province (2021KWZ-09), and Transportation Science and Technology Projects in Shandong Province (2019B55-1).

\section{References}

[1] H. Yang, K. Ozbay, and O. Ozturk, "Work zone safety analysis and modeling: a state-of-the-art review," Traffic Injury Prevention, vol. 16, no. 4, pp. 387-396, 2015.

[2] A. Karim and H. Adeli, "Radial basis function neural network for work zone capacity and queue estimation," Journal of Transportation Engineering, vol. 129, no. 5, pp. 494-503, 2003.

[3] C. H. Chen and P. Schonfeld, "Work zone lengths for a fourlane road with an alternate route," Journal of Transportation Engineering, vol. 131, no. 10, pp. 780-789, 2005.

[4] Y. Tang and S. I. J. Chien, "Scheduling work zones for highway maintenance projects considering a discrete time-cost relation," Transportation Research Record, vol. 2055, pp. 21-30, 2008.

[5] J. Weng and Q. Meng, "Estimating capacity and traffic delay in work zones: an overview," Transportation Research Part C: Emerging Technologies, vol. 35, pp. 34-45, 2013.

[6] J. Weng and Q. Meng, "Analysis of driver casualty risk for different work zone types," Accident Analysis \& Prevention, vol. 43, no. 5, pp. 1811-1817, 2011.

[7] W. A. Sarasua, W. J. Davis, D. B. Clarke, J. Kottapally, and P. Mulukutla, "Evaluation of interstate highway capacity for short-term work zone lane closures," Maintenance Management and Services, pp. 85-94, 2004.

[8] J. F. Morgan, A. R. Duley, and P. A. Hancock, "Driver responses to differing urban work zone configurations," Accident Analysis and Prevention, vol. 42, no. 3, pp. 978-985, 2010.

[9] F. La Torre, L. Domenichini, and A. Nocentini, "Effects of stationary work zones on motorway crashes," Safety Science, vol. 92, pp. 148-159, 2017.

[10] Y. Bai and Y. Li, "Determining the drivers' acceptance of EFTCD in highway work zones," Accident Analysis \& Prevention, vol. 43, no. 3, pp. 762-768, 2011.

[11] Y. Chung, H. Kim, and M. Park, "Quantifying non-recurrent traffic congestion caused by freeway work zones using 
archived work zone and ITS traffic data," Transportmetrica, vol. 8, no. 4, pp. 307-320, 2012.

[12] X. Chen, L. Qi, Y. Yang et al., "Video-based detection infrastructure enhancement for automated ship recognition and behavior analysis," Journal of Advanced Transportation, vol. 2020, Article ID 7194342, 2020.

[13] J. Whitmire II, J. F. Morgan, T. Oron-Gilad, and P. A. Hancocka, "The effect of in-vehicle warning systems on speed compliance in work zones," Transportation Research Part F: Traffic Psychology and Behaviour, vol. 14, no. 5, pp. 331-340, 2011.

[14] K. Heaslip, M. Jain, and L. Elefteriadou, "Estimation of arterial work zone capacity using simulation," Transportation LettersThe International Journal of Transportation Research, vol. 3, no. 2, pp. 123-134, 2011.

[15] S. Racha, M. Chowdhury, W. Sarasua, and Y. Ma, "Analysis of work zone traffic behavior for planning applications," Transportation Planning and Technology, vol. 31, no. 2, pp. 183-199, 2008.

[16] D. Yang, L. Zhu, L. Ma, and R. Sun, "Model for the capacity of the urban signal intersection with work zone," Journal of Advanced Transportation, vol. 50, no. 7, pp. 1506-1519, 2016.

[17] S. Dong, H. Wang, D. Hurwitz, G. Zhang, and J. Shi, "Nonparametric modeling of vehicle-type-specific headway distribution in freeway work zones," Journal of Transportation Engineering, vol. 141, no. 11, 2015.

[18] S. Hooshdar and H. Adeli, "Toward intelligent variable message signs in freeway work zones: neural network model," Journal of Transportation Engineering, vol. 130, no. 1, pp. 83-93, 2004.

[19] J. Weng and Q. Meng, "Ensemble tree approach to estimating work zone capacity," Transportation Research Record, vol. 2286, pp. 56-67, 2012.

[20] X. Chen, H. Chen, Y. Yang et al., "Traffic flow prediction by an ensemble framework with data denoising and deep learning model," Physica A-Statistical Mechanics and its Applications, vol. 565, 2021.

[21] B. Wu, Y. Tang, X. Yan, and C. Guedes Soares, "Bayesian Network modelling for safety management of electric vehicles transported in RoPax ships," Reliability Engineering and System Safety, vol. 209, 2021.

[22] X. Yang, Y. Lu, and Y. Lin, "Optimal variable speed limit control system for freeway work zone operations," Journal of Computing in Civil Engineering, vol. 31, no. 1, 2017.

[23] M. Shakouri, L. H. Ikuma, F. Aghazadeh, and S. Ishak, "Drivers' merging behavior data in highway work zones," Data in Brief, vol. 6, pp. 829-832, 2016.

[24] C. Silverstein, J. Schorr, and S. H. Hamdar, "Work zones versus nonwork zones: risk factors leading to rear-end and sideswipe collisions," Journal of Transportation Safety and Security, vol. 8, no. 4, pp. 310-326, 2016.

[25] Q. Meng and J. Weng, "Evaluation of rear-end crash risk at work zone using work zone traffic data," Accident Analysis and Prevention, vol. 43, no. 4, pp. 1291-1300, 2011.

[26] J. Weng, Q. Meng, and X. Yan, "Analysis of work zone rearend crash risk for different vehicle-following patterns," Accident Analysis and Prevention, vol. 72, pp. 449-457, 2014.

[27] Y. Li and Y. Bai, "Highway work zone risk factors and their impact on crash severity," Journal of Transportation Engineering, vol. 135, no. 10, pp. 694-701, 2009.

[28] J. Weng and Q. Meng, "Rear-end crash potential estimation in the work zone merging areas," Journal of Advanced Transportation, vol. 48, no. 3, pp. 238-249, 2014.
[29] Y. Li and Y. Bai, "Development of crash-severity-index models for the measurement of work zone risk levels," Accident Analysis and Prevention, vol. 40, no. 5, pp. 1724-1731, 2008.

[30] L. Domenichini, F. La Torre, V. Branzi, and A. Nocentini, "Speed behaviour in work zone crossovers: a driving simulator study," Accident Analysis and Prevention, vol. 98, pp. 10-24, 2017.

[31] K. Zhang, S. Batterman, and F. Dion, "Vehicle emissions in congestion: comparison of work zone, rush hour and freeflow conditions," Atmospheric Environment, vol. 45, no. 11, pp. 1929-1939, 2011.

[32] B. Wu, J. Zhang, T. L. Yip, and C. Guedes Soares, "A quantitative decision-making model for emergency response to oil spill from ships," Maritime Policy and Management, vol. 48, no. 3, pp. 299-315, 2021.

[33] JTG D20-2017: Design Specification for Highway Alignment, 2018.

[34] JTG H30-2015: Safety Work Rules for Highway Maintenance, 2015.

[35] S. G. Charlton, "The role of attention in horizontal curves: a comparison of advance warning, delineation, and road marking treatments," Accident Analysis and Prevention, vol. 39, no. 5, pp. 873-885, 2007.

[36] JTG B05-2015: Specifications for Highway Safety Audit, 2016.

[37] C. Zhang, H. Zhang, X. Ma, M. Zhang, and S. Wang, "Driving risk assessment in work zones using cloud model," Mathematical Problems in Engineering, vol. 2018, Article ID 8759580, 2018.

[38] D. Yang, S. Y. Zheng, C. Wen, and P. J. Jin, "A dynamic lanechanging trajectory planning model for automated vehicles," Transportation Research Part C: Emerging Technologies, vol. 95, pp. 228-247, 2018.

[39] E. Blana, "Driving Simulator Validation Studies: A Literature Review," Institute of Transport Studies University of Leeds, Leeds, UK, 1996.

[40] J. Tornros, "Driving behaviour in a real and a simulated road tunnel-a validation study," Accident Analysis and Prevention, vol. 30, no. 4, pp. 497-503, 1998. 